\title{
Analytical Determination of the Lag Phase in Grapes by Remote Measurement of Trellis Tension
}

\author{
Julie M. Tarara ${ }^{1}$, Bernardo Chaves, Luis A. Sanchez, \\ and Nick K. Dokoozlian \\ USDA-ARS, Horticultural Crops Research Unit, 24106 N. Bunn Road, \\ Prosser, WA 99350
}

Additional index words. logistic model, vineyard, sensitivity analysis, Vitis vinifera, sigmoid curve

\begin{abstract}
The lag phase $(L)$ of grape berry growth is used to determine the timing of hand sampling for yield estimation. In commercial practice, growers apply scalars to measurements of berry of cluster masses under the assumption that fruit was assessed during $L$, which is the short period of slowest increase in fruit mass that occurs between the first and second sigmoid curves that describe growth in fleshy fruits. To estimate $L$, we used an automated remote system that indirectly detects increases in vegetative and fruit mass in grapevines by monitoring the tension $(T)$ in the main load-bearing wire of the trellis. We fitted logistic curves to the change in $T(\Delta T)$ such that the parameters could be interpreted biologically, particularly the onset of $L$ : the asymptotic deceleration of growth. Curves fit the data well [root mean square error (RMSE) 4.2 to 14.9] in three disparate years and two vineyards. The onset of $L$ was most sensitive to the inflection point of the first logistic curve but relatively insensitive to its shape parameter. The analytical solution of the second derivative of the first logistic curve for its minimum predicted the apparent onset of $L$ with a range of 3 to 5 days among replicates. The roots of the third derivative allowed analytical solutions for the onset of the first rapid growth phase and $L$, consistently predicting the onset of $L 2$ to 15 days earlier than was identified by trained observers who examined $\Delta T$ curves. Remote sensing of $\Delta T$ could better time field sampling and decrease current reliance on visual and tactile assessment to identify the onset of $L$, thus improving yield estimation in grapes.
\end{abstract}

Grape (Vitis spp.) berries exhibit a longunderstood biphasic pattern of growth common among fleshy fruits (e.g., Connor, 1919; see reviews by Coombe, 1976; Williams and Matthews, 1990). Lag phase is a period of variable duration in which there is little increase in mass or volume of the fruit. It is the asymptotic deceleration of berry growth that separates the initial period of rapid growth after anthesis from the second period of rapid growth during fruit maturation. The onset of $L$ is the prompt for manual sampling as applied in traditional yield estimation in vineyards, where fruit clusters are counted (e.g., Wulfsohn et al., 2012) and weighed. This process must be completed before the second period of rapid growth starts. In short, growers must sample large acreages very rapidly - on the order of days and with a limited number of staff. The $L$ is categorized formally by green

Received for publication 11 Jan. 2013. Accepted for publication 27 Feb. 2013.

We thank Paul E. Blom for collection and initial post-processing of the data.

Mention of trade names or commercial products in this article is solely for the purpose of providing specific information and does not imply recommendation or endorsement by the U.S. Department of Agriculture.

${ }^{1}$ To whom reprint requests should be addressed; e-mail julie.tarara@ars.usda.gov. berries on the cusp of softening [modified Eichhorn-Lorenz (E-L) stage 33; Coombe, 1995]; physiologically, seedcoats begin to harden and embryos begin to mature. Field scouting relies heavily on subjective visual and tactile assessments to determine whether berries are at $L$. Inherent ambiguity, which is not trivial, is compounded by asynchronous development of berries within a cluster (Coombe and Bishop, 1980; Gray and Coombe, 2009). Scaling factors that have been developed over decades require input values of fruit mass during $L$ to produce repeatable yield predictions. Computational details often are not disclosed for proprietary reasons; general approaches are described more often in the gray than in the scientific literature (Clingeleffer et al., 2001; Hellman and Casteel, 2003; May 1972; Price and Lombard, 1988; Wolpert and Vilas, 1992).

We developed an automated system that provides a remote and dynamic indicator of annual vegetative and fruit growth, or increase in mass, and thus an opportunity to identify the onset of $L$ analytically. Briefly, the trellis tension monitor (TTM; Tarara et al., 2004) continuously detects $T$ in a load-bearing trellis wire. From $\Delta T$ between budbreak and harvest one can infer the annual pattern of growth, or increase in mass, of the canopy and fruit. At the beginning of the season this increase represents rapid vegetative growth, whereas from soon after berry set, $\Delta T$ is progressively dominated by the increase in fruit mass, even under well-watered conditions (see review, Tarara et al., 2009; Williams et al., 2010; Williams and Matthews, 1990). Under naturally drying soils (e.g., Lebon et al., 2006) and under deficit irrigation (Williams et al., 2010), which is practiced worldwide in irrigated wine grape production, the dominance of $\Delta T$ by fruit growth can be inferred earlier because early water deficits are imposed in part to limit vegetative growth.

Given the continuous output from the TTM, one could determine the time of onset of $L$ dynamically from $\Delta T$. We hypothesized that it is possible to find analytical solutions to $\Delta T$ over time to identify the onset of $L$ from the first sigmoid curve of berry growth. We further hypothesized that these estimates would be more consistent, at finer temporal resolution, and earlier than is typically resolved by human observation. Our objective was to fit nonlinear curves to TTM data such that the parameters could be interpreted with biological meaning and the onset of $L$ could be determined independently of existing heuristics. Application of TTM data specifically to yield estimation will be presented in a forthcoming article.

\section{Materials and Methods}

Site description. Data were collected over three years (2007-09) in two commercial vineyards near Waterford, CA (lat. $37.66^{\circ} \mathrm{N}$, long. $120.83^{\circ} \mathrm{W} ; 41 \mathrm{~m}$ above sea level). Average annual rainfall (1988-2011) in the area is $300 \mathrm{~mm}$ (State of California, http:// wwwcimis.water.ca.gov) with dry summers and wet winters. Both vineyards were planted in 1994 on Teleki 5C rootstock with $3.05 \mathrm{~m}$ between rows and $2.44 \mathrm{~m}$ between vines for an average plant density of 1345 vines/ha. Experimental rows were on average $420 \mathrm{~m}$ long (Vineyard 1) and $250 \mathrm{~m}$ long (Vineyard 2). The vines in Vineyard 1 (Vitis vinifera $\mathrm{L}$. 'Merlot'; 22.32 ha) were in rows oriented north-south, whereas those in Vineyard 2 ( $V$. vinifera 'Chardonnay'; 30.68 ha) were oriented east-west. In both vineyards, vines were trained to a unilateral cordon (horizontal extension of the trunk) at $\approx 1.1 \mathrm{~m}$ aboveground and were dormant-pruned annually to two-bud spurs spaced 15 to $20 \mathrm{~cm}$ apart, from which the new shoots emerged. Five-year average yields (2007-11) in both vineyards were $\approx 22 \mathrm{t} \cdot \mathrm{ha}^{-1}$. The trellis included a single horizontal support wire (galvanized, commercial Class $3 ; 2.30 \mathrm{~mm}$ diameter; $11 \mathrm{AWG}$ [American Wire Gauge]) at the height of the cordon, hereafter referred to as the cordon wire or load-bearing trellis wire. At every vine trunk there was one steel stake (t-post) to which the cordon wire was fixed by a wire loop of the same diameter as the trellis wire. End posts were anchored circular steel pipe (10 $\mathrm{cm}$ diameter). Shoots were trained in a loose vertical arrangement using a central catch wire at $25 \mathrm{~cm}$ above the cordon wire and two foliage wires at $56 \mathrm{~cm}$ above the cordon wire spaced $43 \mathrm{~cm}$ apart by a horizontal, 
steel cross member with guide notches but no other restrictions on the wire.

The soil in Vineyard 1 was a Hanford sandy loam ( $0 \%$ to $3 \%$ slope, Coarse-loamy, mixed, superactive, nonacid, thermic Typic Xerorthents) and that in Vineyard 2 was a Madera sandy loam [0\% to $9 \%$ slope, Fine, smectitic, thermic Abruptic Durixeralfs; (USDA-NRCS, http://websoilsurvey.nrcs.gov)]. Vines were managed under regulated deficit irrigation between fruit set and the time at which a composite sample of fruit had a soluble solids concentration of $18^{\circ}$ Brix. The deficit regimen was applied at weekly intervals $80 \%$ of estimated crop evapotranspiration $\left(\mathrm{ET}_{\mathrm{c}}\right)$ as determined by an on-site weather station. Irrigation was delivered by drip. Between $18^{\circ}$ Brix and harvest, $100 \% \mathrm{ET}_{\mathrm{c}}$ was applied to minimize fruit dehydration and thus loss of yield. The effect of deficit irrigation was observed in that shoot apices had been desiccated, indicating no further elongation of the shoots; furthermore, no shoot growth was observed after the return of the vines to irrigation at $100 \%$ of $\mathrm{ET}_{\mathrm{c}}$. Fruit was harvested on average at $24.9^{\circ}$ Brix in Vineyard 1 and at $23.1^{\circ}$ Brix in Vineyard 2. All cultural practices including pest and disease interventions were performed according to commercial standards for wine grapes in the area.

In 2007, per commercial practice, excess shoots were thinned manually to facilitate solar radiation penetration into the canopy in Vineyard 1 only, $\approx 2$ weeks before fruit set (Table 1). Basal leaves were removed (standard commercial practice) mechanically in 2007 and in $2009, \approx 2$ weeks after fruit set in Vineyard 2 and $\approx 3$ weeks after fruit set in Vineyard 1 with an average loss of $0.63 \mathrm{~kg}$ total fresh weight per vine. The timing of leaf removal in Vineyard 2 resulted in collateral loss of 4.5 clusters per vine (3.4\%) on average. Negligible fruit loss was observed in Vineyard 1 because clusters were substantially larger at the time. Neither shoot thinning nor leaf removal was performed in 2008 because a late spring freeze had defoliated the vines overnight on days of year (DOY) 111 to 112 (20 to 21 Apr.).

We recorded growth and developmental stages at 7- to 10-d intervals, and with similar frequency, we measured indicators like shoot length and mass and fruit mass $(n=20$ shoots $)$. The onset of $L$, which historically is estimated manually with substantial ambiguity, was defined as the date at which half of sampled berries was soft to the touch with the remainder hard and green (modified E-L stages 33 to 34 ). The onset of ripening (end of $L)$ was defined as the date at which at least half of a sample of berries from sentinel vines exhibited color change in addition to softening (E-L stage 35). Immediately before the vineyard was harvested by machine, the experimental vines (five to each side of each TTM) were harvested by hand, the fruit was weighed, and clusters were counted.

Instrumentation and model development. In each vineyard in 2007, one TTM system was installed per row in three consecutive rows; the arrangement was replicated in another section of each field for a total of 12 TTMs in the experiment. Temperaturecompensated load cells (RSCA-C1-1K; HBM, Inc., Marlboro, MA) were installed in line with the cordon wire by cutting the wire between two vines, creating crimped loops for attachment of the instrument assembly, then tightening the wire manually by a turnbuckle. Trellis wire temperature was measured with a copper-constantan thermocouple [Type T; $0.5 \mathrm{~mm}$ diameter (24-AWG)] glued to the underside of the cordon wire. One data logger (CR-1000, Campbell Scientific, Logan, UT) was dedicated to each set of three TTMs. Signals were scanned every $5 \mathrm{~s}$ and averaged every $15 \mathrm{~min}$. Data were recorded continuously from installation in 2007 through dormant pruning in 2010.

The TTM data were post-processed as detailed previously (Blom and Tarara, 2009; Tarara et al., 2004). Initial conditions $\left(T_{0}\right)$ were set to zero just after budbreak for each TTM in each year. We used as $T_{0}$ the average $T$ for 1 week before an increase in $T$ was detected by the sensor. Given the length of wire, it was not possible to achieve identical $T_{0}$ among rows. The difference between $\Delta T$ at the current time and $T_{0}$ was plotted in daily time steps $\left(\Delta T_{d}\right)$. Use of $\Delta T$ normalized the data between years and for the variation in initial wire tension among rows.

Temporal analyses were conducted using finite differences after we had applied a 48-h moving average to $\Delta T_{d}$. Double monomolecular, logistic, and Gompertz sigmoid functions were fitted to the observed $\Delta T_{d}$ data (Hau et al., 1993); the best-fitting curves were found by adjusting the parameters of a double logistic equation under the following conditions:

$$
\begin{aligned}
\Delta T_{d}= & I+\frac{\alpha_{1}}{\left(1+e^{-k_{1}\left(d-\gamma_{1}\right)}\right)} \text { if } d<\beta \\
\Delta T_{d}= & \frac{\alpha_{1}}{\left(1+e^{-k_{1}\left(\beta-\gamma_{1}\right)}\right)} \\
& +\frac{\alpha_{2}}{\left(1+e^{-k_{2}\left(d-\gamma_{2}\right)}\right)} \text { if } d \geq \beta
\end{aligned}
$$

where $\Delta T_{d}$ is in daily time steps; $\beta$ is the intersection between Eqs. [1] and [2]; $I$ is the intercept of Eq. [1]; $\alpha_{1}$ is the projected maximum $\Delta T$ up to $\beta ; k_{1}$ and $k_{2}$ are shape parameters; $\gamma_{1}$ and $\gamma_{2}$ are inflection points; and $\alpha_{2}$ is the projected maximum $\Delta T_{d}$ after $\beta$, where $\beta$ is expressed either as DOY or thermal time in degree-days from January 1 (DD; base $10^{\circ} \mathrm{C}$ ). The point $d=\beta$, the initial value of the second function, was interpreted biologically as the onset of ripening by accepted convention in the literature (e.g., Coombe, 1976; Coombe and McCarthy, 2000; Matthews et al., 1987b; Williams and Matthews, 1990) supported by periodic field observation (Table 1). Input data consisted of 36 sets of daily TTM output. The double logistic curves were fitted for each TTM in each vineyard in each year, and an average curve was fitted for each vineyard in each year.

The onset of $L$ was defined as the time at which the second derivative of Eq. [1] reached its minimum $\left(d_{\mathrm{min}}\right)$ expressed in DOY. Simplifying, let us define $y_{d}=\frac{\alpha_{1}}{1+e^{-k_{1}\left(d-\gamma_{1}\right)}}$; thus,

$$
\frac{\partial^{2} \Delta T_{d}}{\partial d^{2}}=\left(\frac{k_{1}}{\alpha_{1}}\right)^{2} y_{d}\left(\alpha_{1}-y_{d}\right) \cdot\left(\alpha_{1}-2 y_{d}\right)
$$

The $d_{\text {min }}$ represents the beginning of the decrease in the rate of change in $\Delta T_{d}$ after the inflection point $\gamma_{1}$ [Eq. (1)]; in other words, when the velocity of fruit growth approached its minimum value before the onset of ripening. Mathematically, $L$ represents the asymptotic deceleration point in the logistic curve. The roots of the third derivative of Eq. [1] were taken for analytical solution of critical points:

$$
\begin{aligned}
& d_{1}=\gamma_{1}-\ln (2+\sqrt{3}) / k_{1} \\
& d_{2}=\gamma_{1}+\ln (2+\sqrt{3}) / k_{1}
\end{aligned}
$$

\begin{tabular}{|c|c|c|c|c|c|c|c|c|}
\hline \multirow[b]{3}{*}{ Yr } & \multirow[b]{3}{*}{ Vineyard } & \multirow[b]{3}{*}{ Cultivar } & \multicolumn{4}{|c|}{ Developmental stage ${ }^{y}$} & \multirow{2}{*}{$\frac{\text { Cultural practice }}{\text { Leaf removal }}$} & \multirow{3}{*}{$\begin{array}{l}\text { Yield } \\
\mathrm{t} \cdot \mathrm{ha}^{-1}\end{array}$} \\
\hline & & & Budbreak & Fruit set & Onset of ripening & Harvest & & \\
\hline & & & \multicolumn{5}{|c|}{ - } & \\
\hline \multirow[t]{2}{*}{2007} & 1 & Merlot & 20 Mar. (79) & 22 May (142) & 17 July (198) & 11 Oct. (283) & 1 July (182) & 24.7 \\
\hline & 2 & Chardonnay & 16 Mar. (75) & 15 May (135) & 9 July (190) & 29 Aug. (241) & 30 May (150) & 25.6 \\
\hline \multirow[t]{2}{*}{2008} & 1 & Merlot & 26 Mar. (86) & 4 June (156) & 24 July (206) & 8 Oct. $(282)$ & N/A & 13.1 \\
\hline & 2 & Chardonnay & 13 Mar. (73) & 4 June (156) & 5 July (187) & 18 Aug. (231) & N/A & 8.5 \\
\hline \multirow[t]{2}{*}{2009} & 1 & Merlot & 30 Mar. (89) & $\mathrm{ND}^{\mathrm{x}}$ & 9 July (190) & 6 Oct. (279) & 22 June (173) & 31.0 \\
\hline & 2 & Chardonnay & 23 Mar. (82) & 24 May (144) & 9 July (190) & 7 Sep $(250)$ & 9 June $(160)$ & 36.1 \\
\hline
\end{tabular}

where $d_{1}$ is the onset of the most rapid rate of increase before the inflection point $\gamma_{1}$ and $d_{2}$

Table 1. Estimated dates of grapevine developmental stages and vineyard cultural practices that were relevant to changes in tension $(\Delta T)$ in the main load-bearing trellis wire as assessed by field scouting (7- to 10-d intervals) according to established protocols of the commercial cooperator. ${ }^{z}$

${ }^{\mathrm{z}}$ Yield per vineyard was defined as total fruit delivered and weighed at the winery. The efficiency of the machine harvest was not considered.

${ }^{\mathrm{y}}$ Where necessary, linear interpolation between field scouting dates that indicated $0 \%$ and $100 \%$ observation of the defined criteria.

${ }^{\mathrm{x}} \mathrm{ND}=$ not determined; $\mathrm{N} / \mathrm{A}=$ not applicable. 
is the time of termination of rapid growth after $\gamma_{1}$. The difference $\left(d_{2}-d_{1}\right)$ is approximated as the duration of the linear portion of the logistic growth curve. When $I=0, d_{1}$ is $21.1 \%$ of the function's maximum (i.e., $\alpha_{1}$ ) and $d_{2}$ is $78.9 \%$ of $\alpha_{1}$ (Gregorczyk, 1991). These percentages increase or decrease depending on the value of $I$ relative to $\alpha_{1}$. The $d_{2}$ is the date of onset of $L$. Derivation of Eqs. $[3,4]$ can be found in the Appendix. From Eq. [4] the onset of $L$ was calculated for each TTM ( $\mathrm{n}=24)$ and for vineyard-averaged functions. Data from 2008 were excluded from this analysis because the second budbreak after the catastrophic freeze caused a grossly unrepresentative growth function and compressed developmental cycle, which limited comparative analyses among years.

A pragmatic evaluation was devised between the analytical solution for $L$ and that which might be used by vineyard managers in applying the TTM approach as a decision aid. Two trained observers (L.S., J.T.) examined plots of $\Delta T_{d}$ (heuristic approach) to identify the "shoulder" of the first logistic curve [Eq. (1)] for each TTM in both vineyards for 2007 and 2009. The 2008 data were omitted from this exercise because the very small $k$ in the compressed growth curves essentially prohibited visual identification of $d_{2}$ [Eq. (4b)] from $\Delta T_{d}$. Observations that had been made by field scouting at less regular and/or less frequent intervals were used only for supplemental post hoc reference to on-farm practices (Table 1).

\section{Statistical analyses}

Double logistic curves representing specific stages of berry growth were adjusted using PROC NLIN with Gauss Newton optimization in SAS (SAS Institute Inc., 2008) applying a limit of 2000 iterations. Analysis of variance of $\Delta T_{d}$ and asymptotic confidence intervals for each estimated parameter were calculated. First, second, and third derivatives of Eq. [1] were calculated for each TTM and the minimum of Eq. [3] was solved to identify the onset of $L$. The RMSE was computed and the test of normality was applied to the residuals of each adjusted curve. Values of the onset of $L$ for either individual TTMs or for vineyard-averaged curves are reported as a function of DOY and as a percentage of the upper asymptote $\left(\alpha_{1}\right)$ of Eq. [1]. A sensitivity analysis of $L$ was conducted from Eqs. [4a, 4b] by varying parameters $k_{1}$ and $\gamma_{1}$, from 0.06 to 0.12 by 0.01 for $k_{1}$ and from DOY 145 to 169 by 1 for $\gamma_{1}$, resulting in 175 simulations. Analysis of variance was computed for main and interaction effects among parameters using PROC GLM (SAS Institute Inc., 2008).

\section{Results}

Description of fitted curves. In both vineyards and in all years, aggregated RMSE for adjusted curves indicated acceptable goodness of fit for double logistic functions (Table 2). The models' residuals were normally distributed (data not shown). Noticeable deviations between observed and adjusted values (Fig. 1) occurred around $d=0$ because of the sensitivity of the TTM system to small changes in mass $\left(\Delta T_{\mathrm{d}}-\Delta T_{\mathrm{d}-1}\right)$ during the time at which the load-bearing trellis wire supported little mass: budbreak through early shoot growth. Consequently, the variability among $I$ (Table 2 ) is not unexpected. In some instances, $\Delta T_{\mathrm{d}}$ and its modeled value diverged near harvest $\left(\alpha_{1}+\alpha_{2}\right)$ indicating a degree of dehydration in the fruit that reduced the mass supported by the load-bearing wire.

High variability in yield among years (Table 1) was reflected both in the maximum $\Delta T_{\mathrm{d}}$ at harvest and in its parameter estimates $\alpha_{1}+\alpha_{2}$ in both vineyards (Table 2 ). Nonetheless, key parameters between 2007 and 2009 were similar for Eq. [1], indicating symmetrical rates of growth and development about $\gamma_{1}$, a characteristic of the generalized logistic curve (Gregorczyk, 1991). Interannual variability in fruit mass before ripening is indicated by $\alpha_{1}$, where $2009>2007$. In Eq. [2], the intermediate yields of 2007 are reflected in intermediate parameter estimates $\left(\alpha_{1}+\alpha_{2}\right)$ in both vineyards $(2009>2007>>2008)$.

The shape parameters $\left(k_{1}, k_{2}\right)$ represent average rates of increase in $\Delta T_{d}$ in the two logistic curves or each of the two main growth periods of the fruit. One may define a $k^{\prime}$ as an apparent average rate of growth for the period. The inflection points $\left(\gamma_{1}, \gamma_{2}\right)$ are the dates at which $\Delta T_{d}$ reaches the null point of acceleration for the respective curve; in other words, the point at which growth begins to slow. The $k_{l}$ ' includes increases in vegetative mass before fruit set followed by a small amount of vegetative mass plus rapidly increasing fruit mass between fruit set and $L$. The $k_{2}$ ' is nearly exclusively fruit growth because under deficit irrigation, vegetative growth can be considered negligible during this period (e.g., Matthews et al., 1987a, 1987b; Williams et al., 2010). Within 2 to 3 weeks after fruit set, average shoot length approached an asymptote $(\approx 90 \mathrm{~cm}$, Vineyard $1 ; \approx 120 \mathrm{~cm}$, Vineyard 2; Fig. 2). At that time, clusters accounted for $44 \%$ to $57 \%$ of the sum of canopy and fruit mass. Less than 4 weeks after the onset of ripening, cluster mass accounted for $81 \%$ to $87 \%$ of the sum of fruit and canopy mass (data not shown). In all years, $k_{I}$ ' in 'Merlot' exceeded that of 'Chardonnay' but the reverse was true at $d>\beta$, except in 2008. Under the conditions imposed on Eqs. $[1,2], \beta$ defines the start of the second logistic curve and thus indicates the onset of ripening (Boss et al., 1996; Coombe and McCarthy, 2000; Matthews et al., 1987a).

Despite the late initiation of secondary growth in 2008 , the $\Delta T_{d}$ function was well fitted by the double logistic approach with a few differences in goodness of fit between 2007 and 2009. The $\alpha_{1}$ of 2008 was the lowest of the three years, reflecting smaller canopies and less fruit mass before $\beta$ in both vineyards. The developmental clock "reset" in 2008 resulted in higher $\gamma_{1}$ in 'Merlot' (i.e., later date of maximum rate of growth before $L$ ) although this was not the case for

Table 2. Estimated parameters of the double logistic curves (six per vineyard) fitted to continuous measurements of the change in tension $(\Delta T)$ in the main load-bearing trellis wire in each of two vineyards. $^{\mathrm{z}}$

\begin{tabular}{|c|c|c|c|c|c|c|c|c|}
\hline \multirow{3}{*}{$\frac{\text { Vineyard }}{1}$} & \multirow{3}{*}{$\frac{\text { Cultivar }}{\text { Merlot }}$} & \multirow[b]{2}{*}{ Parameter $^{\mathrm{y}}$} & \multicolumn{6}{|c|}{$\mathrm{Yr}$} \\
\hline & & & \multicolumn{2}{|c|}{ 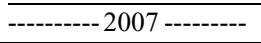 } & \multicolumn{2}{|c|}{------ 2008 ------ } & \multicolumn{2}{|c|}{--------- 2009 -------- } \\
\hline & & & DOY & DD & DOY & $\mathrm{DD}^{\mathrm{x}}$ & DOY & DD \\
\hline & & $I$ & 22.25 & 15.19 & -9.05 & - & 8.44 & 13.63 \\
\hline & & $\alpha_{1}$ & 436 & 434 & 345 & - & 576 & 548 \\
\hline & & $k_{1}$ & 0.1069 & 0.0108 & 0.0649 & - & 0.0992 & 0.0107 \\
\hline & & $\gamma_{1}$ & 153 & 742 & 165 & - & 155 & 754 \\
\hline & & $\beta$ & 188 & 1178 & 190 & - & 180 & 1180 \\
\hline & & $\alpha_{2}$ & 263 & 259 & 86.0 & - & 322 & 310 \\
\hline & & $k_{2}$ & 0.1289 & 0.0095 & 0.172 & - & 0.1149 & 0.0093 \\
\hline & & $\gamma_{2}$ & 207 & 1454 & 209 & - & 212 & 1487 \\
\hline & & RMSE & 6.43 & 6.77 & 4.23 & N/A & 8.24 & 11.64 \\
\hline \multirow[b]{2}{*}{ Vineyard } & \multirow[b]{2}{*}{ Cultivar } & \multirow[b]{2}{*}{ Parameter } & \multicolumn{6}{|c|}{ Yr } \\
\hline & & & \multicolumn{2}{|c|}{----------2007 --------- } & \multicolumn{2}{|c|}{------ 2008 ------ } & \multicolumn{2}{|c|}{----------- 2009 --------- } \\
\hline \multirow[t]{10}{*}{2} & Chardonnay & & DOY & DD & DOY & $\mathrm{DD}$ & DOY & DD \\
\hline & & $I$ & 17.09 & 64.31 & -22.68 & - & 12.04 & 12.72 \\
\hline & & $\alpha_{1}$ & 454 & 467 & 364 & - & 697 & 709 \\
\hline & & $k_{1}$ & 0.0899 & 0.0087 & 0.0574 & - & 0.0784 & 0.0074 \\
\hline & & $\gamma_{1}$ & 151 & 716 & 149 & - & 147 & 666 \\
\hline & & $\beta$ & 185 & 1200 & 185 & - & 180 & 1215 \\
\hline & & $\alpha_{2}$ & 153 & 212 & 59.8 & - & 229 & 182 \\
\hline & & $k_{2}$ & 0.2002 & 0.0098 & 0.1515 & - & 0.1578 & 0.0121 \\
\hline & & $\gamma_{2}$ & 200 & 1281 & 198 & - & 202 & 1382 \\
\hline & & RMSE & 5.11 & 5.76 & 6.78 & N/A & 11.84 & 14.91 \\
\hline
\end{tabular}

${ }^{\mathrm{z}}$ Models were constructed using daily time steps $\left(\Delta T_{d}\right)$ in each of three years. The curves were fitted as a function of calendar time [day of year (DOY)] and thermal time [degree-days (DD)].

yThe subscripts ${ }_{1,2}$ refer to the first and second logistic curves, respectively. Parameters of the logistic functions: $I$ is the intercept; $\alpha$ is the upper asymptote; $k$ is a shape parameter; $\gamma$ is the inflection point; and $\beta$ is the intersection between the two functions.

×2008 data expressed as DD from 1 Jan. were excluded because of the catastrophic freeze that caused secondary budbreak 4 to 6 weeks later than the long-term average.

$\mathrm{RMSE}=$ root mean square error; $\mathrm{N} / \mathrm{A}=$ not applicable. 


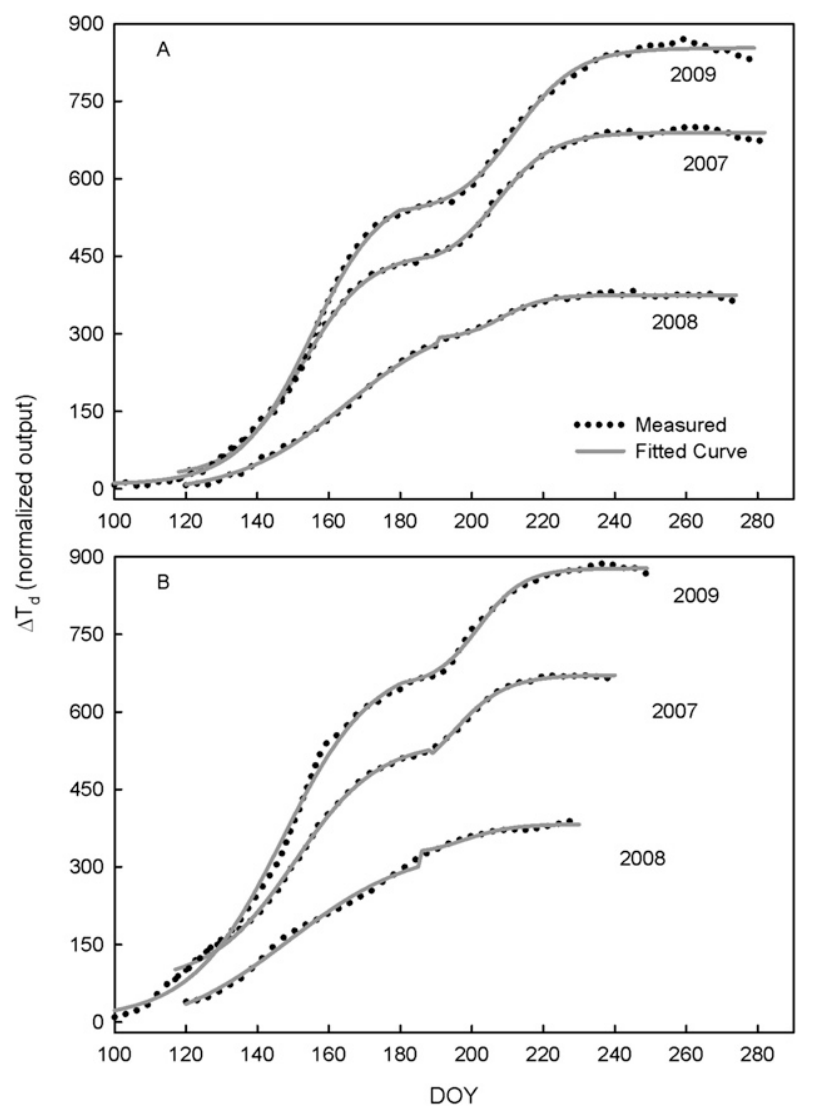

Fig. 1. Adjusted double logistic curves fitted to the average change in tension in daily time steps $\left(\Delta T_{\mathrm{d}}\right)$ in the main load-bearing trellis wire of grapes. (A) Vineyard 1 ('Merlot') and (B) Vineyard 2 ('Chardonnay'). The 'Chardonnay' field was harvested 30 to $50 \mathrm{~d}$ before that of 'Merlot'.

'Chardonnay'. Anthesis is known to be later in 'Merlot' than in 'Chardonnay' as is the onset of fruit ripening. The substantially lower yields were reflected clearly in lower $\alpha_{1}+\alpha_{2}$ in both cultivars. There was a smaller gain in fruit mass during ripening: $\alpha_{2}$ was $33 \%$ of its value in 2007 for 'Merlot' ( $27 \%$ in 2009 ) and $39 \%$ of its value in 2007 for 'Chardonnay' (26\% in 2009).

The fitted curves set $d=\beta$ to within $4 \mathrm{DD}$ across years for Vineyard $1($ DOY range $=10 \mathrm{~d})$. In Vineyard $2, d=\beta$ was within $15 \mathrm{DD}$ between 2007 and 2009 , but $\approx 100$ DD earlier in 2008 (DOY range $5 \mathrm{~d}$ ). Despite advantages of evaluating rates of development by thermal time, growers continue to rely on calendar time for interannual comparisons. It appears that TTM data represented well the annual patterns of vegetative and reproductive growth as exemplified by: 1) interannual variability in yield (Table 1 ); 2) shoot growth that was characteristic of deficit irrigation (Fig. 2); and 3) cluster mass measured from before $L$ to just before harvest of the cooperator's earliest cultivars (Fig. 3). The timing of the rapid slowing and cessation of shoot growth indicates that the deficit irrigation practice for vegetation control was successful. Others have demonstrated similar patterns (e.g., Matthews et al., 1987a).

Sensitivity analysis. After simulation, the analysis of variance of model parameters $k_{1}$ and $\gamma_{1}$ showed the estimate of $L$ to be most sensitive to $\gamma_{1}$; in other words, the maximum of $\partial \Delta T / \partial d$ or the inflection point of Eq. [1]. The $\gamma_{1}$ accounted for $79.7 \%$ of the total sums of squares $\left(\mathrm{SS}_{\text {tot }}\right)$, whereas $k_{1}$ represented $20.3 \%$ of $\mathrm{SS}_{\text {tot }}$. The onset of $L$ occurred later for higher $\gamma_{1}$ in a linear fashion. The magnitude of variation was almost constant (Fig. 4). The onset of $L$ was inversely but weakly driven by $k_{1}$. In other words, with a rapidly growing crop (high $k_{1}$ ), the inflection point of Eq. [1] and $L$ are temporally closer than when $k_{1}$ is small (i.e., slower rate of growth). Given consistent management practices, values of $k_{1}$ are dependent on environmental conditions, particularly temperature and solar radiation. Global irradiance expressed cumulatively was significantly higher in 2009 than in 2007 between late March and late July (CIMIS; data not shown). However, mean monthly temperature was lower in 2009 than 2007 after budbreak but higher in 2009 around the time of bloom. The largest differences in temperature between 2007 and 2009 (2009> 2007) occurred between approximately DOY 140 and DOY 165 (CIMIS; data not shown), the approximate period between fruit set and the onset of $L$

Determination of the onset of $\mathrm{L}$ between analytical and heuristic approaches. Between analytical and heuristic methods, variances differed (data not shown) in the dates identified as the onset of $L$, suggesting inconsistency between the two approaches. In all but three of 36 instances, the observers' identifications were later than were the analytical solutions. There was not a high correlation $(r=0.55)$ in the identified onset of $L$ between approaches although that correlation was statistically significant $(P=0.01)$. It is important to note that the methods are hardly equivalent and the slope of the regression line was not unity (1.45). By individual TTM, the difference between observer and algorithmselected dates ranged from -5 to $+15 \mathrm{~d}$ with an absolute mean difference of $6.7 \mathrm{~d}( \pm 3.33$ [SD]; Table 3). The TTM data had been postprocessed such that the effects of environmental transients were removed (Tarara et al., 2004) but there remained some noise in $\Delta T_{d}$. Some curves appeared flat to the observers (i.e., low $k_{1}$, meaning more time between $\gamma_{1}$ and $L$ ). For conciseness, exemplary $\Delta T$ curves are presented to illustrate ambiguity for the trained observers in selecting the onset of $L$ (Figs. 5 and 6). Uncertainties like these may prompt an observer to integrate into a selection his or her prior knowledge or perceptions; in other words, when $L$ "should" begin. In this exercise we attempted to reduce bias by selecting one trained observer with no a priori knowledge of the typical date of the onset of $L$ at the study location.

One might expect that evaluating fitted curves rather than assessing post-processed instrument output would reduce uncertainty for trained observers. However, when presented with the mean annual adjusted logistic curve of each vineyard, our observers also selected dates that were later than $d_{2}$ [Eq. (4b)]. In 2007, although $d_{2}$ was DOY 165 for 'Merlot', the trained observers' selection was $4 \mathrm{~d}$ later. In the same year, the algorithm identified DOY 165 for 'Chardonnay', whereas the observers selected DOY 173. In 2009, the observers' selection was $8 \mathrm{~d}$ later than $d_{2}$ for 'Merlot' (DOY 167 vs. DOY 175). For 'Chardonnay' the difference was $4 \mathrm{~d}$ (DOY 163 by analytical solution; DOY 167 by observer selection). At $d_{2}, \Delta T_{d}$ on average was $82 \%$ (2007) of $\alpha_{1}$ for 'Merlot' ( $84 \%$ in 2009) and $83 \%$ (2007) for 'Chardonnay' ( $81 \%$ in 2009). The observers' selections fell closer to the asymptote of Eq. [1]: $89 \%$ of $\alpha_{1}$ in 'Merlot' in both years and 91\% of $\alpha_{1}$ (2007) in 'Chardonnay' (84\% in 2009). Thus, the observers' selections were closer to $\beta$, the start of the second logistic curve, which implies less time available for the traditional manual sampling between $L$ and $\beta$.

\section{Discussion}

One advantage of a logistic modeling approach is the opportunity to infer biological meaning from the parameters (e.g., Gregorczyk, 1991; Mischan et al., 2011). There are other statistically valid doublesigmoid models, including the combination of classical sigmoid curves (e.g., Gompertz, Richards), bilinear, and others [e.g., Génard and Bochou, 1993, for peach (Prunus persica L. Batsch)]. These approaches may be more or less parsimonious than a double logistic model (Buchwald, 2007). We chose the double logistic approach because data in daily 


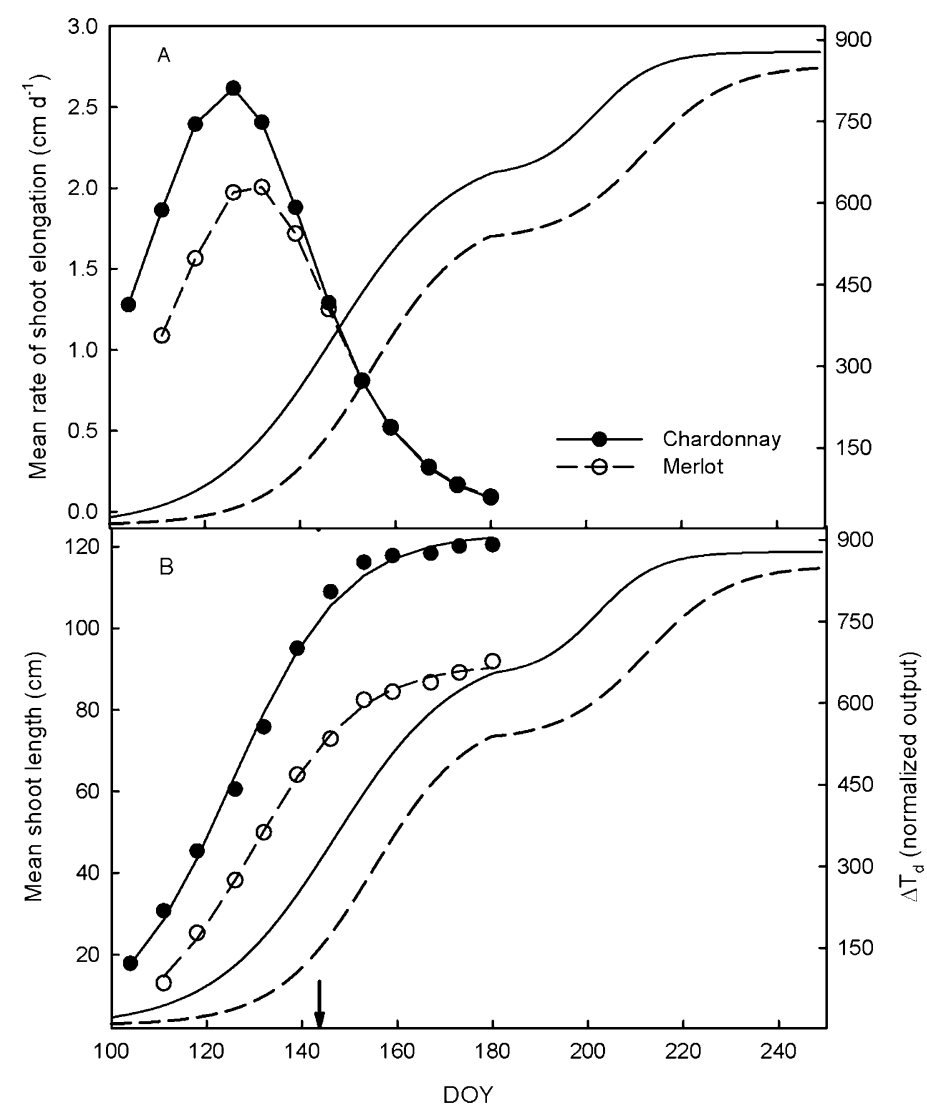

Fig. 2. Exemplary average (A) rates of shoot elongation and $(\mathbf{B})$ shoot length $(n=20)$ for two cultivars in adjacent vineyards (2009). Shoots were measured on vines in the same rows as the trellis tension monitors. Logistic curves were fitted to the shoot length data. The change in tension in daily time steps $\left(\Delta T_{d}\right)$ represents the average fitted curve for each cultivar. Arrow denotes the estimated date of fruit set (by field scouting) in 'Chardonnay'; fruit set in 'Merlot' was estimated as 1 week later. Regulated deficit irrigation was initiated during the irrigation cycle of day of year (DOY) 139 to 146.

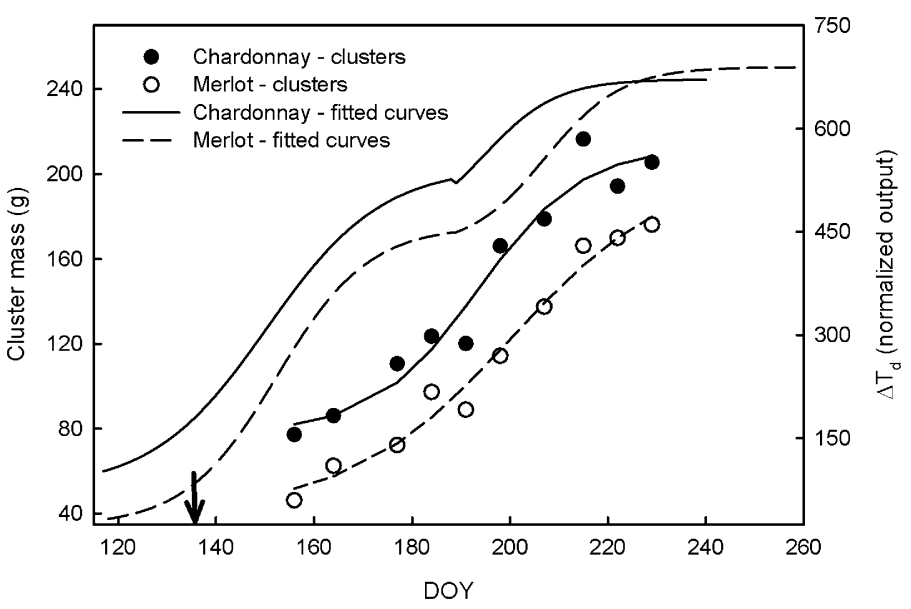

Fig. 3. Exemplary average cluster mass $(n>50)$ for two cultivars in adjacent vineyards (2007). The change in tension in the load-bearing wire in daily time steps $\left(\Delta T_{d}\right)$ represents the average fitted curve for each cultivar. Clusters were collected from vines in the same rows as the trellis tension monitors and were weighed individually. An apparent decrease in cluster mass at day of year (DOY) 192 is the result of an error in sampling protocol in which clusters were collected across the vineyard. Arrow denotes estimated dates of fruit set in 'Chardonnay' by field scouting. Fruit set in 'Merlot' was estimated as 1 week later.

time steps offered enough df for robust parameter estimates, those curves provided the best fits, and their parameters could be interpreted biologically.
Agriculture-National Agricultural Statistics Service, 2011). In 2008 one consequence of the late freeze was exceptionally small yields (within $6 \%$ of the lowest yields per hectare over the last 30 years) because the crop was borne from less fruitful secondary buds (Dry, 2000; Sánchez and Dokoozlian, 2005). Despite similar yields between two cultivars, there was less time between the onset of ripening and commercial harvest for 'Chardonnay' than for 'Merlot'; hence, higher $k$ ' at $d>\beta$. 'Chardonnay' is described as an earlyripening cultivar with compact clusters of small berries, whereas 'Merlot' is described as ripening midseason. Under non-limiting conditions, 'Merlot' clusters are small with berries larger than those of 'Chardonnay' (Reynier, 2003). However, the regulated deficit irrigation imposed on red wine cultivars is applied also to restrict berry size and alter fruit composition (e.g., Kennedy et al., 2002; Ojeda et al., 2002; Roby and Matthews, 2004). Vineyard 2 was harvested 30 to $50 \mathrm{~d}$ earlier than Vineyard 1, resulting in less time for deficit-induced restriction of berry growth in 'Chardonnay'.

That the onset of ripening was $\approx 100 \mathrm{DD}$ earlier in 2008 than in 2007 or 2009 suggests an unusually accelerated rate of development for 'Chardonnay' berries (Vineyard 2). However, the values of $k_{2}$ were to the contrary; rates of growth did not appear to have been accelerated. In work where dates of anthesis were manipulated (Coombe, 1980), logistic curves for berry volume diverged by $\approx 3$ weeks after fruit set. This effect was attributed to different rates and timing of the deceleration of berry growth $\left(\gamma_{1}\right.$ in our fitted curves, the null point in the acceleration of growth) and to the duration of $L$ : the growth of late-forming berries decelerated quickly and these berries exhibited a relatively protracted $L$. Those results support the $\Delta T_{d}$ curves that we observed in 2008. Nonetheless, there is some inherent difficulty in interpreting parameter estimates expressed as DD in 2008 because the post-freeze growth and development cycle (i.e., secondary budbreak in late April to early May) was substantially different from that of the historical biological cycle at that location (budbreak in early March). At the time of the second budbreak, mean temperatures were higher and thermal time was accumulating faster than at the time of the long-term average budbreak. The same was true of daily total global irradiance. Therefore, DD comparisons among years in this respect are not particularly meaningful and we did not list parameter estimates by DD in 2008 (refer to Table 2).

Aside from consequences that are specifically related to the date of flowering (Coombe, 1980), the rate of berry growth also is sensitive to temperature after fruit set (Soar et al., 2009). Excessively high temperatures could reduce the rate of growth, which would be represented by smaller $k_{1}$ in a logistic model. In a controlled-environment experiment, anthesis was delayed by high temperature, the rate of berry growth decelerated 


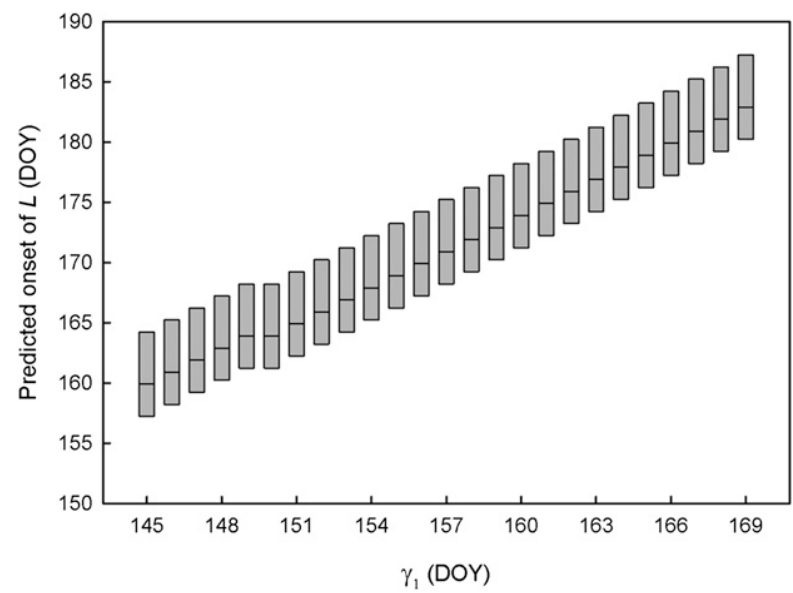

Fig. 4. Results of sensitivity analysis (175 simulations) of the solution of Eq. [3] $\left(\delta^{2} \Delta \mathrm{T} / \delta d^{2}\right)$ for its minimum to estimate the date of the onset of lag phase of berry growth $(L)$ as a function of $\gamma_{1}$ (inflection point) and $k_{1}$ (shape parameter, average rate of increase). Simulations were made by varying $k_{1}$ between 0.060 and 0.120 in steps of 0.002 , and $\gamma_{1}$ between 145 and 169 by 1 . Data were pooled for all sensors in both vineyards across 2007 and 2009.

Table 3. Date of onset of the lag phase $(L)$ of fruit growth in grapes as estimated by analytical solution of Eq. [3] for its minimum and by trained observers examining post-processed data from the daily change in tension $\left(\Delta T_{d}\right)$ in the load-bearing wire of the trellis in each of two vineyards. ${ }^{z}$

\begin{tabular}{|c|c|c|c|c|c|c|c|c|}
\hline & & & $\begin{array}{c}L \text { by } \\
\text { trained } \\
\text { observer }\end{array}$ & $\Delta T_{d}$ calculated & $\begin{array}{c}\text { Fraction } \\
\text { of } \alpha_{1}\end{array}$ & $\begin{array}{c}L \text { by } \\
\text { analytical } \\
\text { solution }\end{array}$ & $\Delta T_{d}$ calculated & $\begin{array}{c}\text { Fraction } \\
\text { of } \alpha_{1}\end{array}$ \\
\hline Cultivar & $\mathrm{Yr}$ & TTM & $\overline{\text { DOY }}$ & $\overline{\text { normalized output }}$ & $\overline{(\%)}$ & $\overline{\text { DOY }}$ & $\overline{\text { normalized output }}$ & $\overline{(\%)}$ \\
\hline \multirow[t]{12}{*}{ Merlot } & 2007 & 1 & 167 & 397 & 83.6 & 165 & 381 & 80.3 \\
\hline & & 2 & 168 & 361 & 90.6 & 164 & 337 & 84.6 \\
\hline & & 3 & 167 & 398 & 84.4 & 165 & 384 & 81.4 \\
\hline & & 4 & 168 & 362 & 90.9 & 163 & 331 & 83.2 \\
\hline & & 5 & 173 & 430 & 98.7 & 166 & 389 & 89.2 \\
\hline & & 6 & 168 & 398 & 94.1 & 164 & 367 & 86.8 \\
\hline & 2009 & 1 & 177 & 480 & 96.2 & 167 & 413 & 82.8 \\
\hline & & 2 & 177 & 519 & 94.6 & 166 & 445 & 81.2 \\
\hline & & 3 & 173 & 549 & 95.6 & 164 & 474 & 82.5 \\
\hline & & 4 & 173 & 499 & 87.4 & 169 & 462 & 81.0 \\
\hline & & 5 & 177 & 522 & 95.2 & 169 & 462 & 81.5 \\
\hline & & 6 & 173 & 486 & 87.5 & 168 & 448 & 80.8 \\
\hline \multirow[t]{12}{*}{ Chardonnay } & 2007 & 1 & 173 & 403 & 88.3 & 165 & 361 & 79.2 \\
\hline & & 2 & 175 & 321 & 90.0 & 166 & 280 & 78.5 \\
\hline & & 3 & 173 & 463 & 87.7 & 163 & 403 & 76.4 \\
\hline & & 4 & 172 & 496 & 90.4 & 167 & 467 & 86.4 \\
\hline & & 5 & 173 & 428 & 90.9 & 166 & 386 & 81.4 \\
\hline & & 6 & 174 & 421 & 90.0 & 164 & 370 & 80.0 \\
\hline & 2009 & 1 & 172 & 600 & 92.6 & 164 & 531 & 82.1 \\
\hline & & 2 & 158 & 518 & 71.3 & 163 & 585 & 80.6 \\
\hline & & 3 & 172 & 674 & 90.9 & 164 & 604 & 81.6 \\
\hline & & 4 & 178 & 682 & 95.7 & 163 & 588 & 82.5 \\
\hline & & 5 & 160 & 484 & 76.4 & 161 & 508 & 80.1 \\
\hline & & 6 & 160 & 476 & 81.7 & 165 & 485 & 83.2 \\
\hline
\end{tabular}

${ }^{z}$ The parameter $\alpha_{1}$ is the upper asymptote of the logistic curve [Eq. (1)] that ends at the onset of fruit ripening. Results from pooled data are presented in the text.

$\mathrm{TTM}=$ trellis tension monitor; DOY $=$ day of year.

earlier, and $L$ was lengthened (Hale and Buttrose, 1974).

It is the grower or winery's goal to complete fruit sampling during $L$ and as well before the onset of ripening as possible because scaling values are based on fruit mass at $L$. The consequence of ill-timed sampling, which in practice usually is too close to $\beta$, is that small changes in fruit mass can lead to unacceptably large errors in harvest mass (Clingeleffer et al., 2001) per field, the unit implementing them entails recognized uncertainties: inconsistencies in executing sampling protocols among individuals or between years and reliance on subjective assessment of key variables. For example, to determine the onset of $L$, visual and tactile assessments of berries are the methods of choice for simplicity and speed. Ambiguity is caused by operational definitions (e.g., 50\% of sample hard and green, $50 \%$ just soft to touch) even when those definitions are consistent with formal classification systems. Staff also are influenced by experience and fatigue among other factors. Some protocols call for berry dissection to examine the color of seedcoats. Although this technique may reduce interpretation errors, its practicality is diminished as farm size increases, where rapid sampling becomes paramount. Another accepted limitation of field scouting is its relatively limited frequency: some growth or developmental stages may pass threshold criteria between site visits. Continuous monitoring systems address this longstanding limitation.

The onset of ripening is easier to determine heuristically than is $L$, because it comprises definitive berry softening plus a visual indicator: color change, which is obvious in dark-skinned cultivars. Like with $L$, sampling frequency adds a source of error. In the present study, the cooperator's staff's estimates of the onset of ripening (see Table 1) were 2 to $10 \mathrm{~d}$ later than $\beta$ with the exception of 'Merlot' in 2008 ( $16 \mathrm{~d}$ later). Novel work in response to some of these limitations is using two- and three-dimensional visualization systems to estimate fruit numbers and/or volumes in grape clusters (Dunn and Martin, 2004; Nuske et al., 2011) and individual spherical fruits [e.g., apple (Malus $\times$ domestica Borck.); Stajnko et al., 2009; Zhou et al., 2012] based on the relative ease of discerning red fruit from green leaves.

In summary, fitted logistic models of $\Delta T$ are influenced most by the responsiveness of the load-bearing wire to changes in plant mass. Post-processing of the raw data renders the detection system relatively insensitive to environmental transients (Tarara et al., 2004). For estimating the onset of $L$, full implementation of a tension-monitoring approach in practice would require an extensive database of $\Delta T$ vs. $d$ relationships because model parameters varied by cultivar and to some extent by year, which reflects consequences of genetic variability, meteorological variability, and a nearly 18-month developmental cycle for the fruit. Farm managers would need to develop experience in interpreting $\Delta T$ data relative to antecedent years. If using the initial post-processed data, residual noise could increase the degree of difficulty for the grower to precisely select benchmarks like the onset of $L$. A useful application would be self-correcting logistic equations, meaning dynamic adjustments of parameter estimates such that $L$ may be identified as a fraction of $\alpha_{1}$ or as a predicted distance between $\gamma_{1}$ and $\beta$. With several years' data, average parameter values could 


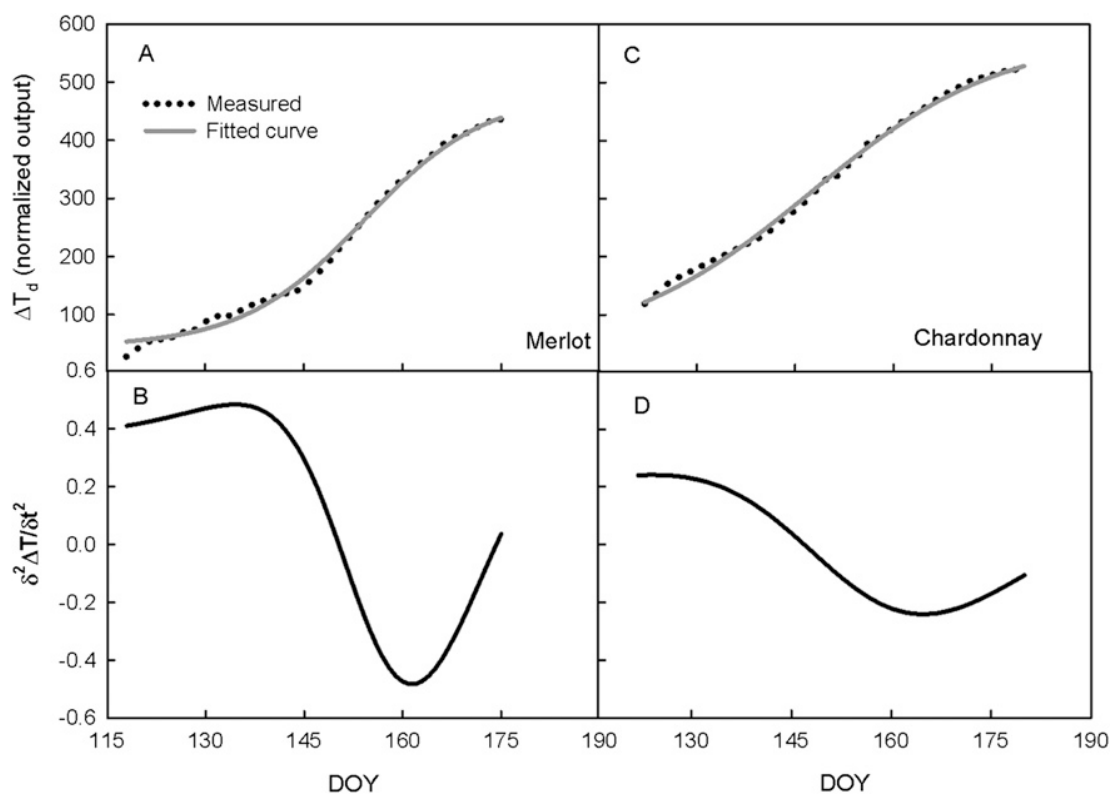

Fig. 5. The change in tension in the load-bearing trellis wire in daily time steps $\left(\Delta T_{d}\right)$ and fitted logistic curves (first sigmoid curve only; A, C) from exemplary individual instruments (2007) to illustrate trained observers' perceived ambiguity in the slope of the curve around the onset of the lag phase $(L)$ of berry growth. In these cases, the observers' selections were $11 \mathrm{~d}$ (DOY 173, 'Merlot') and $5 \mathrm{~d}$ (DOY 172 , 'Chardonnay') later than the dates identified by analytical solution of Eq. [3] ( $\left.\delta^{2} \Delta T / \delta d^{2}\right)$ for its minimum $(\mathbf{B}, \mathbf{D})$.

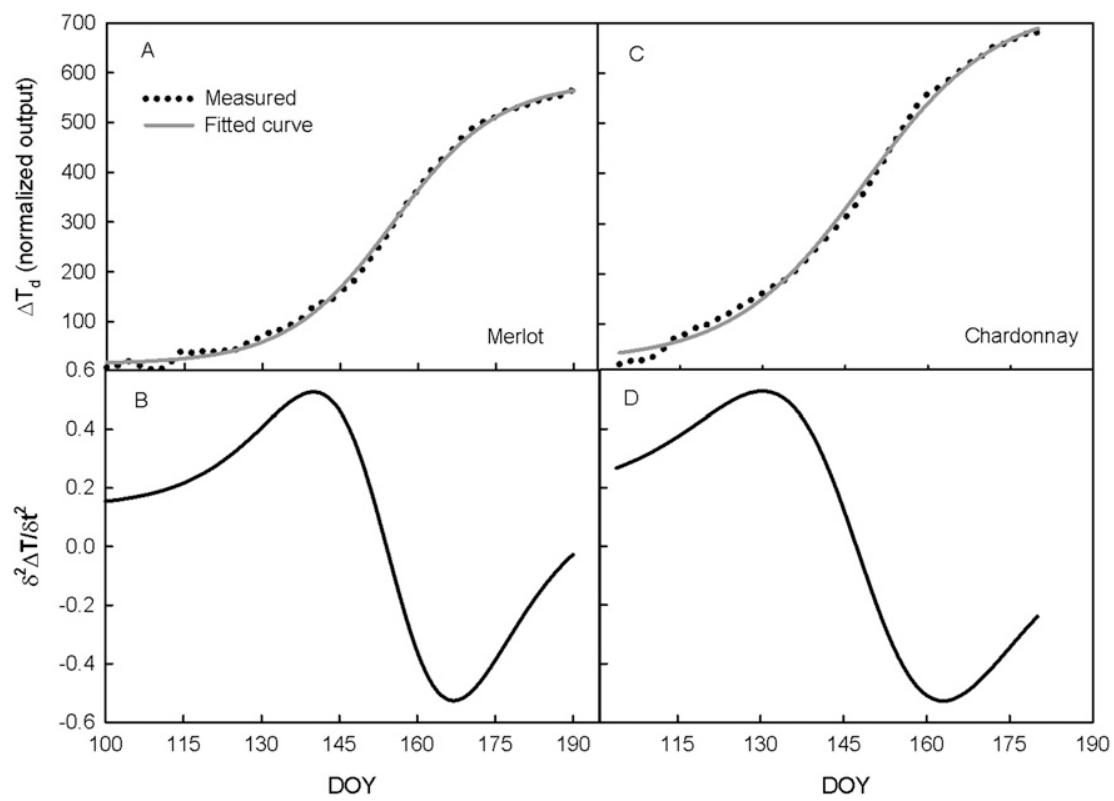

Fig. 6. The change in tension in the load-bearing trellis wire in daily time steps $\left(\Delta T_{d}\right)$ and fitted logistic curves (first sigmoid curve only) from exemplary individual instruments (2009) to illustrate trained observers' perceived ambiguity in the slope of the curve around the onset of the lag phase $(L)$ of berry growth (A, C). In these cases, the observers' selections were $9 \mathrm{~d}$ (DOY 177, 'Merlot') and $15 \mathrm{~d}$ (DOY 178 , 'Chardonnay') later than the dates identified by analytical solution of Eq. [3] $\left(\delta^{2} \Delta T / \delta d^{2}\right)$ for its minimum $(\mathbf{B}, \mathbf{D})$.

be set as initial conditions to derive these models.

Double logistic curves adequately described $\Delta T_{d}$ in the primary load-bearing wire of a vineyard trellis during the growing season. From the pattern of $\Delta T_{d}$, inferences were made about annual vegetative growth and reproductive growth and development. The first logistic curve encompassed the time represented in the first logistic curve. This implies a possibility of predicting $L$ soon after fruit set from equations with tolerance for variation in the parameters $I$ (intercept) and $\alpha_{1}$ (upper asymptote). Timely identification of $L$ is the linchpin of current (traditional) methods of estimating yield in vineyards. Compared with selections made by trained observers, as might occur in a commercial setting, analytical solutions for the onset of $L$ consistently were earlier. By monitoring $\Delta T_{d}$, the resolution of estimating the onset of $L$ is finer than that which can be derived from present coarse methods of field scouting. Analytical solutions to the first logistic curve of $\Delta T_{d}$ can be used to support the timing of manual sampling and to confirm field observations. Use of a remote technique to infer the annual growth pattern and to resolve a key developmental stage has the potential to improve the industry's most intensive efforts to identify $L$ and subsequently estimate yield at the field scale.

\section{Literature Cited}

Blom, P.E. and J.M. Tarara. 2009. Trellis tension monitoring improves yield estimation in vineyards. HortScience 44:678-685.

Boss, P.K., C. Davies, and S.P. Robinson. 1996. Analysis of the expression of anthocyanin pathway genes in developing Vitis vinifera $\mathrm{L}$. cv Shiraz grape berries and the implications for pathway regulation. Plant Physiol. 111:10591066.

Buchwald, P. 2007. A general bilinear model to describe growth or decline time profiles. Math. Biosci. 205:108-136.

Clingeleffer, P., G.M. Dunn, M. Krstic, and S Martin. 2001. Crop development, crop estimation and crop control to secure quality and production of major wine grape varieties: A National Approach. Project number CSH 96/1. Final Report to Grape and Wine Research and Development Corporation. CSIRO and Victoria NRE.

Connor, C.H. 1919. Report on fruit conditions and experimental work. Section F. Report of the Department of Horticulture. NJ Agr. Expt. Sta. Annu. Rpt. 40. p. 82-88.

Coombe, B.G. 1976. The development of fleshy fruits. Annu. Rev. Plant Physiol. 27:207-228.

Coombe, B.G. 1980. Development of the grape berry. I. Effects of time of flowering and competition. Aust. J. Agr. Res. 31:125-131.

Coombe, B.G. 1995. Adoption of a system for identifying grapevine growth stages. Aust. J. Grape Wine Res. 1:100-110.

Coombe, B.G. and G.R. Bishop. 1980. Development of the grape berry. II. Changes in diameter and deformability during veraison. Aust. J. Agr. Res. 31:499-509.

Coombe, B.G. and M.G. McCarthy. 2000. Dynamics of grape berry growth and physiology of ripening. Aust. J. Grape Wine Res. 6:131-135.

Dry, P. 2000. Canopy management for fruitfulness. Aust. J. Grape Wine Res. 6:109-115.

Dunn, G.M. and S.R. Martin. 2004. Yield potential from digital image analysis: A technique with potential for vineyard assessment prior to harvest. Aust. J. Grape Wine Res. 10:196198.

Génard, M. and C. Bochou. 1993. A functional and exploratory approach to studying growth: The example of the peach fruit. J. Amer. Soc. Hort. Sci. 118:317-323. 
Gray, J.D. and B.G. Coombe. 2009. Variation in Shiraz berry size originates before fruit set but harvest is a point of resynchronisation for berry development after flowering. Aust. J. Grape Wine Res. 15:156-165.

Gregorczyk, A. 1991. The logistic function - its application to the description and prognosis of plant growth. Acta Societatis Botanicorum Poloniae 60:67-76.

Hale, C.R. and M.S. Buttrose. 1974. Effect of temperature on ontogeny of berries of Vitis vinifera L. cv. Cabernet Sauvignon. J. Amer. Soc. Hort. Sci. 99:390-394.

Hau, B., L. Amorin, and A. Bergamin Filho. 1993. Mathematical functions to describe disease progress curves of double sigmoid pattern. Phytopathology 83:928-932.

Hellman, E.W. and T. Casteel. 2003. Crop estimation and thinning, p. 231-234. In: Hellman, E.W. (ed.). Oregon viticulture. Oregon State Univ. Press, Corvallis, OR.

Kennedy, J.A., M.A. Matthews, and A.L. Waterhouse. 2002. Effect of maturity and vine water status on grape skin and wine flavonoids. Amer. J. Enol. Viticult. 53:268-274.

Lebon, E., A. Pellegrino, G. Louarn, and J. Lecouer. 2006. Branch development controls leaf area dynamics in grapevine (Vitis vinifera) growing in dry soil. Ann. Bot. (Lond.) 98:175-185.

Matthews, M.A., M.M. Anderson, and H.R. Schultz. 1987a. Phenologic and growth responses to early and late season water deficits in Cabernet franc. Vitis 26:147-160.

Matthews, M.A., G. Cheng, and S.A. Weinbaum. 1987b. Changes in water potential and dermal extensibility during grape berry development. J. Amer. Soc. Hort. Sci. 112:314-319.

May, P. 1972. Forecasting the grape crop. Austral. Wine Brewing and Spirit Review. 25: 46-48.

Mischan, M.M., S. Zambello de Pinho, and L. Raquel de Carvalho. 2011. Determination of a point sufficiently close to the asymptote in nonlinear growth functions. Scientia Agr. (Piracicba, Braz.) 68:109-114.

Nuske, S., S. Achar, T. Bates, S. Narasimhan, and S. Singh. 2011. Yield estimation in vineyards by visual grape detection. Proc. 2011 IEEE/RSJ Intl. Conf. on Intelligent Robots and Systems (IROS 2011), 25-30 Sept., San Francisco, CA.

Ojeda, H., C. Andary, E. Kraeva, A. Carbonneau, and A. Deloire. 2002. Influence of pre-and postveraison water deficit on synthesis and concentration of skin phenolic compounds during berry growth of Vitis vinifera cv. Shiraz. Amer. J. Enol. Viticult. 53:261-267.

Price, S.F. and P.B. Lombard. 1988. Predicting yield in Oregon vineyards. Proc. II Intl. Cool Climate Vitic. Oenology Symp. Auckland, New Zealand. p. 197-200.

Reynier, A. 2003. Manuel de viticulture. 9th Ed. Lavoisier, Paris, France.

Roby, G. and M.A. Matthews. 2004. Relative proportions of seed, skin and flesh in ripe berries from Cabernet Sauvignon grapevines grown in a vineyard either well irrigated or under water deficit. Aust. J. Grape Wine Res. 10:74-82.

Sánchez, L.A. and N.K. Dokoozlian. 2005. Bud microclimate fruitfulness in Vitis vinifera L. Amer. J. Enol. Viticult. 56:319-329.

SAS Institute Inc. 2008. SAS/STAT ${ }^{\circledR} 9.2$ user's guide. SAS Institute Inc., Cary, NC.

Soar, C.J., M.J. Collins, and V.O. Sadras. 2009. Irrigated Shiraz vines (Vitis vinifera) upregulate gas exchange and maintain berry growth in response to short spells of high maximum field temperature. Funct. Plant Biol. 36:801-814.

Stajnko, D., J. Rakun, and M. Blanke. 2009. Modelling apple fruit yield using image analysis for fruit color, shape and texture. Eur. J. Hort. Sci. 74:260-267.

State of California. California Irrigation Management Information System. 2009. California Department of Water Resources (Office of Water Use Efficiency). 27 Dec. 2012. <http:// wwwcimis.water.ca.gov>.
Tarara, J.M., P.E. Blom, B. Shafii, W.J. Price, and M.A. Olmstead. 2009. Modeling seasonal dynamics of canopy and fruit growth in grapevine for application in automated yield estimation. HortScience 44:334-340.

Tarara, J.M., J.C. Ferguson, P.E. Blom, M. Pitts, and F.J. Pierce. 2004. Estimation of grapevine crop mass and yield via automated measurements of trellis tension. Trans. ASAE 47:647-657.

U.S. Department of Agriculture-National Agricultural Statistics Service. 2011. California historic commodity data: California wine grapes, 1920-2010. 27 Dec. 2012. <http://www. nass.usda.gov/Statistics_by_State/California/ Historical_Data/index.asp $>$.

U.S. Department of Agriculture - Natural Resources Conservation Service. 2003. Web soil survey. 27 Dec. 2012. <http://websoilsurvey.nrcs.usda. gov/app/HomePage.htm $>$.

Williams, L.E., D.W. Grimes, and C.J. Phene. 2010. The effects of applied water at various fractions of measured evapotranspiration on water relations and vegetative growth of Thompson Seedless grapevines. Irrig. Sci. 28:221-232.

Williams, L.E. and M.A. Matthews. 1990. Grapevine. p. 1019-1055. In: Stewart, B.A. and D.R. Nielsen (eds.). Irrigation of agricultural crops. Agronomy Monograph no. 30. ASA-CSSA-SSSA, Madison, WI.

Wolpert, J.A. and E.P. Vilas. 1992. Estimating vineyard yields: Introduction to a simple, twostep method. Amer. J. Enol. Viticult. 43:384388 .

Wulfsohn, D., F.A. Zamora, C.P. Téllez, I.Z. Lagos, and M. García-Fiñana. 2012. Multilevel systematic sampling to estimate total fruit number for yield forecasts. Precis. Agric. 13:256275.

Zhou, R., L. Damerow, Y. Sun, and M.M. Blanke. 2012. Using colour features of cv. 'Gala' apple fruits in an orchard in image processing to predict yield. Precis. Agr. 13:568-580.

\section{Appendix}

\section{Derivation of the lag phase point (L)}

Logistic Equation: $y=\frac{\alpha_{1}}{1+e^{-k_{1}\left(x-\gamma_{1}\right)}}$,

First derivate: $\frac{\partial y}{\partial x}=\frac{k_{1}}{\alpha_{1}} y\left(\alpha_{1}-y\right)$,

Second derivate: $\frac{\partial^{2} y}{x^{2}}=\left(\frac{k_{1}}{\alpha_{1}}\right)^{2} y\left(\alpha_{1}-y\right)\left(\alpha_{1}-2 y\right)=\frac{k_{1}}{\alpha_{1}}\left[\frac{k_{1}}{\alpha_{1}} y\left(\alpha_{1}-y\right)\left(\alpha_{1}-2 y\right)\right]=\frac{k_{1}}{\alpha_{1}} \frac{\partial y}{\partial x}\left(\alpha_{1}-2 y\right)$,

Third derivate: $\frac{\partial^{3} y}{x^{3}}=\frac{k_{1}}{\alpha_{1}}\left[\frac{\partial^{2} y}{\partial x}\left(\alpha_{1}-2 y\right)+\frac{k_{1}}{\alpha_{1}} \frac{\partial y}{\partial x}\left(-2 \frac{\partial y}{\partial x}\right)\right]=\frac{k_{1}}{\alpha_{1}}\left[\frac{\partial^{2} y}{\partial x}\left(\alpha_{1}-2 y\right)-2 \frac{k_{1}}{\alpha_{1}}\left(\frac{\partial y}{\partial x}\right)^{2}\right]$

$=\frac{k_{1}}{\alpha_{1}}\left[\frac{k_{1}^{2}}{\alpha_{1}^{2}} y\left(\alpha_{1}-y\right)\left(\alpha_{1}-2 y\right)\left(\alpha_{1}-2 y\right)-2 \frac{k_{1}^{2}}{\alpha_{1}^{2}} y^{2}\left(\alpha_{1}-y\right)^{2}\right]=\frac{k_{1}^{3}}{\alpha_{1}^{3}}\left[y\left(\alpha_{1}-y\right)\left(\alpha_{1}-2 y\right)^{2}-2 y^{2}\left(\alpha_{1}-2 y\right)^{2}\right]$

$=\frac{k_{1}^{3}}{\alpha_{1}^{3}} y\left(\alpha_{1}-y\right)\left[\left(\alpha_{1}-2 y\right)^{2}-2 y(\alpha-y)\right]=\frac{k_{1}^{3}}{\alpha_{1}^{3}} y\left(\alpha_{1}-y\right)\left[\alpha_{1}^{2}-4 \alpha_{1} y+4 y^{2}-2 \alpha_{1} y+2 y^{2}\right]$

$=\frac{k_{1}^{3}}{\alpha_{1}^{3}} y\left(\alpha_{1}-y\right)\left[\alpha_{1}^{2}-6 \alpha_{1} y+6 y^{2}\right]$ 
To find the minimum of the second derivate, the third derivate equation must be equal cero

$\frac{k_{1}^{3}}{\alpha_{1}^{3}} y\left(\alpha_{1}-y\right)\left[\alpha_{1}^{2}-6 \alpha_{1} y+6 y^{2}\right]=0$, imples $\left[\alpha_{1}^{2}-6 \alpha_{1} y+6 y^{2}\right]=0$,

Using the quadratic equation to solve the equation: $y=\frac{-b \pm \sqrt{b^{2}-4^{*} a c}}{2 a}$

Replacing the terms: $y=\frac{6 \alpha_{1} \pm \sqrt{36 \alpha_{1}^{2}-4 * 6 * \alpha_{1}^{2}}}{2 * 6}=\frac{6 \alpha_{1} \pm \sqrt{12 \alpha_{1}^{2}}}{12}=\frac{6 \alpha_{1} \pm 2 \alpha_{1} \sqrt{3}}{12}=\frac{3 \alpha_{1} \pm \alpha_{1} \sqrt{3}}{6}$

$$
=\alpha_{1}\left(\frac{3 \pm \sqrt{3}}{6}\right) \text {, the roots of the equation are } \alpha_{1}\left(\frac{3+\sqrt{3}}{6}\right) \text { and } \alpha_{1}\left(\frac{3-\sqrt{3}}{6}\right)
$$

Then the third derivate is : $\frac{k_{1}^{3}}{\alpha_{1}^{3}} y\left(\alpha_{1}-y\right)\left[y-\alpha_{1}\left(\frac{3+\sqrt{3}}{6}\right)\right]\left[y-\alpha_{1}\left(\frac{3-\sqrt{3}}{6}\right)\right]$. Let is find $x$,

$\frac{\alpha_{1}}{1+e^{-k_{1}\left(x-\gamma_{1}\right)}}=\alpha_{1}\left(\frac{3+\sqrt{3}}{6}\right) \Rightarrow \frac{1}{1+e^{-k_{1}\left(x-\gamma_{1}\right)}}=\left(\frac{3+\sqrt{3}}{6}\right) \Rightarrow 1+e^{-k_{1}\left(x-\gamma_{1}\right)}=\left(\frac{6}{3+\sqrt{3}}\right)$, rationalizing

$1+e^{-k_{1}\left(x-\gamma_{1}\right)}=\left(\frac{6}{3+\sqrt{3}}\right)\left(\frac{3-\sqrt{3}}{3-\sqrt{3}}\right) \Rightarrow 1+e^{-k_{1}\left(x-\gamma_{1}\right)}=6\left(\frac{3-\sqrt{3}}{6}\right)$, then $1+e^{-k_{1}\left(x-\gamma_{1}\right)}=3-\sqrt{3}$, then

$e^{-k_{1}\left(x-\gamma_{1}\right)}=3-\sqrt{3}-1$, then $-k_{1}\left(x-\gamma_{1}\right)=\ln (2-\sqrt{3})$, then $k_{1}\left(x-\gamma_{1}\right)=-\ln (2-\sqrt{3})$, then

$k_{1}\left(x-\gamma_{1}\right)=\ln \left(\frac{1}{2-\sqrt{3}}\right)$, rationalising again: $k_{1}\left(x-\gamma_{1}\right)=\ln (2+\sqrt{3})$ and finaly $x_{1}=\gamma_{1}+\frac{\ln (2+\sqrt{3})}{k_{1}}$

The same pocedure is used for the another root $\alpha_{1}\left(\frac{3-\sqrt{3}}{6}\right)$, to find $x_{2}=\gamma_{1}-\frac{\ln (2+\sqrt{3})}{k_{1}}$

Replacing this two values in the orignal equation we get: $y=\frac{\alpha_{1}}{3-\sqrt{ } 3}$ when $x=\gamma_{1}+\frac{\ln (2+\sqrt{3})}{k_{1}}$ and

$$
y=\frac{\alpha_{1}}{3+\sqrt{ } 3} \text { when } x=\gamma_{1}-\frac{\ln (2+\sqrt{3})}{k_{1}} \text {. }
$$

First value $\left(x_{1}=L\right)$ represents always $78.8675 \%$ of $\alpha_{1}$ and the secondone $\left(x_{2}=M\right)$ the $21.1325 \%$. 